\title{
O patrimônio cultural como documento: reflexões transdisciplinares para novos horizontes na Ciência da Informação'
}

\author{
Cultural heritage as a document: transdisciplinary reflections to \\ new horizons in Information Science
}

Willian Eduardo Righini de SOUZA²

Giulia CRIPPA ${ }^{3}$

\section{RESUMO}

Pretende-se apresentar um panorama dos discursos e ações sobre o patrimônio cultural brasileiro para, em seguida, discutir contribuições e relações que podem ser estabelecidas a partir dos fundamentos da Ciência da Informação. A primeira é a relação entre patrimônio e o conceito de documento, a segunda sobre os processos documentais e o cientista da informação, e a terceira uma abordagem da mediação e apropriação cultural do patrimônio.

Palavras-chave: patrimônio cultural; documento; Ciência da Informação; transdisciplinaridade.

\begin{abstract}
The aim of this paper is to give an overview of the issues and actions on the Brazilian cultural heritage and then to discuss contributions as well as relationships that may be established from the principles of Information Science. The first item is concerned with the relationship between heritage and the concept of document, the second relates the documentary processes and the information scientist and finally, an approach of cultural heritage mediation and appropriation is presented.
\end{abstract}

Keywords: cultural heritage; document; Information Science; transdisciplinarity.

1 Este artigo é resultado da dissertação de mestrado intitulada "Santa Rosa de Viterbo: mediações para uma discussão sobre a idéia de patrimônio cultural", em andamento na Escola de Comunicação e Artes da Universidade de São Paulo. Este projeto é financiado pela Coordenação de Aperfeiçoamento de Pessoal de Nível Superior - CAPES.

2 Mestrando em Ciência da Informação, Escola de Comunicação e Artes, Universidade de São Paulo. São Paulo, SP, Brasil. Correspondência para/Correspondence to: W.E.R. SOUZA. E-mail: <wrighini@yahoo.com.br>.

3 Docente, Ciências da Informação e Documentação da Faculdade de Filosofia, Ciências e Letras de Ribeirão Preto e do Programa de Pós-Graduação em Ciência da Informação, Escola de Comunicação e Artes, Universidade de São Paulo. São Paulo, SP, Brasil. E-mail: <giuliac@ffclrp.usp.br>.

Recebido em 8/7/2009 e aceito para publicação em 21/10/2009. 


\section{INTRODUÇÃO}

conceito moderno de patrimônio é um desenvolvimento das discussões durante e posteriores à Revolução Francesa, no final do século XVIII. Foi a partir desse momento que a noção de patrimônio como propriedade particular e herança paterna estendeu-se para os bens de uma coletividade. Assim, obras de artes e construções antigas, como castelos e igrejas, foram consideradas "a riqueza material e moral do conjunto da nação" (Abreu, 2003a, p.31).

Como a França vivia um momento de instabilidade, em que os vestígios do antigo regime deveriam ser apagados, acentuaram-se as discussões sobre a preservação daquilo que ainda era relevante para a memória da nação. Um exemplo é o surgimento da noção moderna de museu público, que, como finalidade, deveria ensinar civismo e história para a população (Choay, 2001). Fica claro, portanto, como as noções de patrimônio e museu público estão entrelaçadas, como mostra Hooper-Greenhill (2005).

Após esse período, o patrimônio cultural tornouse um tema recorrente na Europa, o que permitiu o desenvolvimento de uma ampla discussão e, consequentemente, bibliografia. Nesse contexto, podemos citar as reflexões de Viollet-le-Duc (2001) e John Ruskin, que, durante o século XIX, repensaram e confrontaram as idéias de preservação e restauração, e a obra de Riegl (1990), O culto moderno dos monumentos, publicada originalmente em 1903, que apresentou os diferentes valores que justificam a preservação histórica e divulgação do patrimônio ${ }^{4}$.

Tendo como referência esse quadro internacional, intelectuais brasileiros ligados ao movimento modernista começaram, no segundo decênio do século XX, a inventariar o nosso patrimônio cultural, as obras e manifestações que identificam e simbolizam o Brasil. Portanto o objetivo deste artigo é apresentar esse percurso nacional em relação ao patrimônio cultural por meio de uma revisão bibliográfica. Posteriormente, já situado o caso brasileiro, pretendemos desenvolver algumas discussões de caráter ensaístico que relacionam as questões inerentes ao patrimônio com temas centrais da Ciência da Informação (C.I.), como o conceito de documento, o tratamento documental, e a mediação e apropriação cultural. Para isso, consideramos tanto os referenciais teóricos desenvolvidos pela C.I., como aqueles provenientes de outras áreas, mas que constantemente dialogam com o campo, até porque, como afirma Rabello (2009), a Ciência da Informação é marcada pela transdisciplinaridade, com influências da Documentação, Biblioteconomia, Museologia, Direito, História, entre outras, que, especialmente no que se refere ao conceito de documento ${ }^{5}$, permitiu uma diversidade de definições que cobrem desde a noção de "textos escritos" de Ranganathan à "informaçãocomo-coisa" de Buckland (1991).

\section{O PATRIMÔNIO CULTURAL BRASILEIRO}

Discutir a constituição de um patrimônio cultural brasileiro, seja em seu nível discursivo ou prático, requer conhecer o contexto em que surgiram alguns questionamentos da identidade nacional, as características que supostamente nos definem e diferenciam como nação. No Brasil, essa preocupação torna-se evidente com o Movimento Modernista, da arte de Tarsila do Amaral, Portinari à literatura de Oswald de Andrade, Manuel Bandeira e principalmente, na conjuntura deste artigo, Mário de Andrade (Bosi, 2007), apesar de anteriormente outros autores também terem buscado símbolos de "brasilidade" em suas obras, como Euclides da Cunha, Lima Barreto, analisados por Sevcenko (2003) e Lobato (2008).

Para uma análise que melhor explicite o movimento, Lafetá (2000) o divide, de forma operatória, em um período em que prevaleceu o projeto estético (década de 1920) e outro, o ideológico (década de 1930). O projeto estético caracterizava-se pela crítica à velha linguagem, oficial, acadêmica, ao mesmo tempo em que incentivava a experimentação, o uso de novas linguagens, incorporando usos populares e regionais. Já a partir da década de 1930, com o aumento da industrialização, imigração e urbanização,

\footnotetext{
4 Para o historiador de arte (1990), os monumentos são divididos em intencionais (criados para a manutenção da memória coletiva) e não intencionais (que adquiriram o status de monumento pela atribuição da sociedade), apresentando valores que justificam sua preservação e divulgação: valor de uso (utilização prática, como para o turismo), valor artístico, valor histórico, valor de novidade (aparência de novo), valor de ancianidade (aparência de antigo) e valor memorial.

5 Etimologicamente, documento deriva do verbo docere, que significa ensinar, instruir, recebendo o sentido de modelo, exemplo e, sobretudo nos séculos XVIII e XIX, de prova (Le Goff, 2003).
} 
a crítica ao Brasil arcaico tornou-se mais acentuada, e o perfil ideológico do movimento mais claro ao discutir "a função da literatura, o papel do escritor, as ligações da ideologia com a arte" (Lafetá, 2000, p. 28).

Até os anos de 1920, a noção de um país novo, tropical, mestiçado era tratada em forma de constrangimento pelos nossos escritores, que, para se aproximar da cultura européia, nos idealizavam, principalmente os índios. O Modernismo supera essa perspectiva, e o que era visto como nossas deficiências, símbolos do atraso, transformam-se em nossas superioridades (Cândido, 2008).

\begin{abstract}
Não se precisaria mais dizer e escrever, como no tempo de Bilac ou do conde Afonso Celso, que tudo aqui é belo e risonho: acentuam-se a rudeza, os perigos, os obstáculos da natureza tropical. $\bigcirc$ mulato e o negro são definitivamente incorporados como temas de estudo, inspiração, exemplo. O primitivismo é agora fonte de beleza e não mais empecilho à elaboração da cultura. Isso na literatura, na pintura, na música, nas ciências do homem (Cândido, 2008, p. 127).
\end{abstract}

No contato com as vanguardas européias, esses intelectuais, interessados pelo futurismo, dadaísmo e surrealismo, entenderam que um rompimento com o passado só teria sentido em um país que apresentasse uma continuidade, tradição. Desse modo, a modernização artística foi acompanhada de um maior envolvimento pela temática do nacionalismo e da política (Fonseca, 2005).

Mesmo considerando as nações européias ocidentais "mais maduras" e "mais civilizadas" (Gonçalves, 2002, p.46), "um certo número de escritores se aplica a mostrar como somos diferentes da Europa e como, por isso, devemos ver e exprimir diversamente as coisas" (Cândido, 2008, p. 129). Tal diferença, principalmente no que se refere ao patrimônio cultural, começou a ser elaborada nas viagens desses intelectuais a Minas Gerais.

Foram eles que denunciaram o abandono das cidades históricas do Estado e começaram a pensar em iniciativas para a preservação dos monumentos. Na década de 1920, depois das visitas de Rodrigo Melo Franco de Andrade, Lúcio Costa, Mário de Andrade, Minas Gerais passou a ser considerada "o berço de uma civilização brasileira" (Fonseca, 2005, p. 92).

interesse por Minas Gerais deve-se ao fato de ser a região onde se concentrava uma grande quantidade de obras arquitetônicas do barroco brasileiro, considerado símbolo da "redescoberta" do Brasil pelos modernistas. Segundo Gonçalves (2002), de 1937 a 1979, a maioria das obras consideradas patrimônio cultural era representante do barroco e, em 1982, 70 \% do patrimônio cultural brasileiro estava localizado em Minas Gerais. "Nesse sentido, a assim chamada "preservação" deve ser pensada como trabalho transformador e seletivo de reconstrução e destruição do passado, que é realizado no presente e nos termos do presente" (Arantes, 1984, p.9).

O interesse pelo barroco mineiro como símbolo de brasilidade pode ser entendido como uma invenção de tradição, que no discurso de continuidade tenta estabelecer um vínculo com um determinado passado histórico. "Por 'tradição inventada' entende-se um conjunto de práticas, normalmente reguladas por regras tácita ou abertamente aceitas; tais práticas, de natureza ritual ou simbólica, visam inculcar certos valores e normas de comportamento através da repetição [...]" (Hobsbawn; Ranger, 2008, p. 9).

Como uma das principais figuras do Modernismo, Mário de Andrade se destaca. Em 1924, viaja a Minas Gerais na "Viagem de descoberta do Brasil". Em 1927, 1928 e 1929, percorre o norte e nordeste do país em suas "Viagens etnográficas". E, ao ir ao encontro do "Brasil autêntico, dos lugares de memória nacional", começa a inventariar o patrimônio cultural brasileiro (Nogueira, 2005, p. 65).

Para Mário, o Brasil se tornaria civilizado quanto mais se afastasse da imitação do modelo europeu, principalmente francês, e criasse sua própria identidade, estabelecesse seus ideais. Dessa maneira, seu olhar se volta para o interior do país, menos ou nada contaminado pelo espírito da Belle Époque, tão presente em cidades como a capital Rio de Janeiro, analisada por Needell (1993).

Nos registros de sua viagem por Minas Gerais, o poeta expressa a preocupação de preservar aquela arquitetura do século XVIII, grande parte religiosa católica. Ainda, ao não reconhecer na população das pequenas cidades visitadas condições para identificar e dialogar com esse patrimônio descoberto, reafirma o 
papel dos intelectuais modernistas pela guarda da memória nacional (Nogueira, 2005).

Essa posição em relação às populações interioranas não é resultado de um desinteresse por elas, muito pelo contrário. Durante suas viagens etnográficas, uma das maiores preocupações de Mário é "colher e registrar, diretamente da fala do povo, os elementos constitutivos da brasilidade procurada" (Nogueira, 2005, p. 113). Isso revela uma das características que perpassa toda a obra do autor e sua história política: a preocupação com a cultura popular, mesmo que sua concepção de popular esteja, muitas vezes, mais próxima da noção de folclore do que a abrangência com que a compreendemos hoje.

Para colher e registrar as expressões culturais, a fotografia torna-se um dos seus principais instrumentos de trabalho, inclusive na chefia do Departamento de Cultura de São Paulo e na assistência técnica do Serviço do Patrimônio Histórico e Artístico Nacional (SPHAN). Sua metodologia consistia em preservar pela captura da imagem o que era transitório ou que, pela ação do tempo, poderia desaparecer. Além disso, acrescentava a cada fotografia anotações como data, local e nome das pessoas presentes, o que demonstra o detalhamento técnico que permite até os dias atuais a utilização do seu acervo como importante fonte de pesquisa (Nogueira, 2005).

\footnotetext{
À luz do observador, a construção de um projeto nacional modernista pelo inventário do patrimônio cultural, instituiu um novo marco cronológico da História da Cultura Brasileira. Nesse processo, falas, sons, melodias, ritmos, cores, aromas, sabores, saberes, superstições e festas são sentidos físicos e simbólicos do Brasil. Dar uma alma ao Brasil é viajar pelo interior em busca de seu sentido (Nogueira, 2005, p. 175).
}

\section{Dos Discursos às Instituições}

Se a década de 1920 é caracterizada por uma Revolução Intelectual, o decênio seguinte foi marcado por reformas políticas que influenciaram diretamente a temática do patrimônio nacional. Em 1932, aconteceu em São Paulo o movimento revolucionário que dissolveu - Congresso Nacional e pôs fim à vigência da Constituição de 1891. Dessa data até 1937, somente medidas isoladas trataram do patrimônio cultural. Como exemplo, em 1933 foi tombado o conjunto urbanístico de Ouro Preto, em 1934 foi aprovado um novo regulamento para o Museu Histórico Nacional e, no mesmo ano, promulgada a Constituição Federal de 1934, que em seus artigos se referia à necessidade de proteção, pelo Estado, dos objetos de interesse histórico e do patrimônio artístico do país (Gonçalves, 2007).

Em 1937, um golpe de Estado estabeleceu o Estado Novo, um regime autoritário que novamente fechou o Congresso Nacional, assim como os partidos políticos. Em meio à censura e perseguições, o então ministro da Educação e da Saúde, Gustavo Capanema, assume a missão de criar instituições culturais e educacionais (Gonçalves, 2002). Nessa conjuntura de mudanças iniciadas em 1932, são criadas instituições como a Universidade de São Paulo (1934), o Departamento de Cultura de São Paulo (1935), o Instituto do Livro (1937), o Museu Nacional de Belas Artes (1937), entre outros.

Na crise política, intelectuais como Mário de Andrade, Paulo Duarte e Sérgio Millet se filiam ao Partido Democrático. Entre outras propostas, "elegem as questões culturais como solução para os problemas enfrentados pela elite na condução do Brasil moderno" (Nogueira, 2005, p. 200). O envolvimento desses intelectuais com a imprensa e a administração pública e federal permite então que o problema da preservação do patrimônio nacional se transforme em leis e projetos.

No governo Vargas, com a reorganização do Estado, os intelectuais começam a participar da "construção da nação". Em 1936, o então ministro Gustavo Capanema recorre a Mário de Andrade para a elaboração de um anteprojeto para a proteção das obras nacionais. A concepção do autor era ampla. A partir da categoria de "arte", cria oito subcategorias para abranger todos os bens patrimoniais: arqueológica, ameríndia, popular, histórica, erudita nacional, erudita estrangeira, aplicada nacional, aplicada estrangeira (Chagas, 2003). Como se vê, a noção de patrimônio de Mário buscava abranger toda a heterogeneidade brasileira, todas as classes e raças.

No mesmo ano, o anteprojeto foi entregue e aprovado por Gustavo Capanema, que, entretanto, para transformá-lo em projeto, junto com Rodrigo Melo Franco de Andrade, indicado por Mário, e equipe, desenvolveu uma nova versão a ser enviada ao Parlamento (Chagas, 2003). O projeto de lei suprimia 
concepções do anteprojeto, tornava menos abrangente a noção de patrimônio e estabelecia sua forma de proteção, o tombamento. Em 1936, o Serviço do Patrimônio Histórico e Artístico Nacional (SPHAN) começa a funcionar experimentalmente e em 30 de novembro de 1937, pelo Decreto-Lei 25, promulgado pelo presidente Getúlio Vargas, passa a integrar o Ministério da Educação e Saúde (Fonseca, 2005).

Na definição do Decreto-Lei, o patrimônio histórico e artístico nacional é o

[...] conjunto dos bens móveis e imóveis existentes no país e cuja conservação seja de interesse público, quer por sua vinculação a fatos memoráveis da história do Brasil, quer por seu excepcional valor arqueológico ou etnográfico, bibliográfico ou artístico (Brasil, 1937).

No que se refere à preservação dos bens móveis e imóveis, o decreto estabelece quatro Livros do Tombo (Arqueológico, Etnográfico e Paisagístico; Histórico; Belas Artes; Artes Aplicadas), onde as obras consideradas patrimônio nacional devem ser registradas e resguardadas para que não sejam, sem a prévia autorização do SPHAN, destruídas, demolidas, mutiladas, reparadas, pintadas ou restauradas (Brasil, 1937).

O decreto tinha como característica uma solução para o direito de propriedade, que até o momento era um dos fatores que limitavam a preservação do patrimônio, com recusas de diversos projetos pelo Congresso Nacional. Ao contrário da desapropriação, - tombamento manteria a posse do bem pelo proprietário, apenas limitando o seu uso (Gonçalves, 2007).

Desse modo, o que caracteriza o decreto são os recursos operacionais, e o aspecto conceitual e organizacional é a maior contribuição do anteprojeto. Para "viabilizar a prołeção legal era necessário referirse a coisas ('bens móveis e imóveis')", o que levou o SPHAN a trabalhar principalmente com o patrimônio arquitetônico, enquanto outras manifestações culturais, como as folclóricas, por exemplo, pareciam não caber na noção de patrimônio (Fonseca, 2005).

Segundo Chagas (2003), essa não era a concepção de Mário de Andrade. Para o poeta, a reprodução da obra folclórica (provérbios, receitas culinárias, músicas, etc.), sua descrição geral e o registro por filmagem e fotografia também seria uma forma de tombamento, que, ao verificarmos a política do SPHAN, não foi utilizada.

Essa abordagem pode ser comparada com o que Buckland (1991) diz a respeito das obras, objetos e práticas que não podem ser preservados em si em museus, bibliotecas, arquivos ou outras instituições culturais. Para ele, seja o intangível, como crenças, danças e festas, quanto obras imóveis, podem ser representados por documentos/ objetos que os descrevem. Portanto toda informação pode ser "uma coisa" passível de ser registrada, organizada e acessada pela população. $\bigcirc$ importante é que essa "coisa" seja informativa daquilo a que se refere, pois, por meio dessa representação, o observador se aproxima do que quer conhecer. $\bigcirc$ registro torna-se uma representação de um objeto ou prática, que, ao ser classificado como patrimônio, também se torna uma representação de valores selecionados.

O trabalho da instituição privilegiou, no entanto, a arquitetura religiosa dos séculos XVI, XVII e XVIII, primordialmente barroca e mineira. Foi por meio dessa prática que se formularam os critérios para as futuras decisões sobre tombamentos e trabalhos de restauração (Fonseca, 2005), o que causava transtornos aos técnicos quando as obras a serem restauradas não se enquadravam nos limites usuais, como apresentado por Gonçalves (2007), ao discutir a restauração arquitetônica no Estado de São Paulo, dirigida pelo SPHAN.

Não é à toa que a concepção de patrimônio cultural nas primeiras décadas do SPHAN é denominada como a de "pedra e cal":

A imagem que a expressão "patrimônio histórico e artístico" evoca entre as pessoas é a de um conjunto de monumentos antigos que devemos preservar, ou porque constituem obras de arte excepcionais, ou por terem sido palco de eventos marcantes, referidos em documentos e em narrativas dos historiadores. Entretanto, é forçoso reconhecer que essa imagem, construída pela política de patrimônio conduzida pelo Estado por mais de sessenta anos, está longe de refletir a diversidade, assim como as tensões e os conflitos que caracterizam a produção cultural do Brasil, sobretudo a atual, mas também a do passado (Fonseca, 2003, p. 56). 
De 1936 a 1967, o SPHAN foi dirigido por Rodrigo Melo Franco de Andrade, período hoje denominado de "fase heróica" devido ao caráter inovador da instituição, o desconhecimento da maior parte da população sobre as questões patrimoniais e a luta de Rodrigo, com grande prestígio entre intelectuais e funcionários, para uma maior divulgação e sucesso do trabalho realizado.

Nos seus discursos, Melo Franco de Andrade narra o que ele chama de "uma obra de civilização" para o Brasil. Como um país novo, o país necessitaria evoluir de um estágio "mais primitivo" para o "mais avançado", condizente com sua idéia de civilização, ou seja, a civilização européia ocidental. Esse retrato, ao contrário do que possa parecer, não era visto como negativo por Rodrigo. Para ele, esse era apenas um processo pelo qual um país novo deveria passar, que seria superado quando os brasileiros assumissem e defendessem nossa cultura ou tradição. Dessa forma, propõe registrar tudo o que envolve o patrimônio histórico e artístico nacional (Gonçalves, 2002).

Na fase heróica, a decisão sobre o que deveria ser tombado era quase exclusivamente dos funcionários da instituição e seus colaboradores. Como já dissemos, a maior parte da população desconhecia o Serviço e os intelectuais assumiram uma postura de autoridade perante o patrimônio que intimidava interferências externas. Como previsto, o foco das ações foi dirigido para a arquitetura religiosa de Minas Gerais, barroca e católica. Segundo Fonseca (2005, p. 113), "foram tombados, até o ano de 1969, 803 bens, sendo 368 de arquitetura religiosa, 289 de arquitetura civil, 43 de arquitetura militar, 46 conjuntos, 36 bens imóveis, seis bens arqueológicos e quinze bens naturais".

Para Melo Franco de Andrade, a apropriação do patrimônio é a apropriação do passado que represente toda a nação e não somente algumas regiões do país, o que na realidade não aconteceu. Outra preocupação é o que ele considera o processo de desaparecimento do patrimônio histórico e artístico nacional, resultado, segundo crê, da indiferença tanto das massas como das classes mais favorecidas para a necessidade de preservação. Desse modo, a ênfase no seu discurso recai sobre a tarefa de "educar" a população sobre a identidade nacional representada pelo patrimônio (Gonçalves, 2002), apesar de muitos funcionários se afastarem dos canais de difusão do Estado por acreditarem que essa não era uma função da Instituição, reduzindo a visibilidade dos trabalhos apenas para os meios mais intelectualizados (Fonseca, 2005).

Observa-se, nesse período, que os requisitos para o tombamento restringiu-se a informações técnicas, na maioria arquitetônicas, deixando pouco espaço para uma análise da função social dessas obras. Junto a isto, a pouca divulgação do SPHAN e a posição dos técnicos amplamente especializados não permitiu que se pensasse a importância do patrimônio para a sociedade, que de alguma forma também atribui valores aos elementos da cidade.

Em 1967, Rodrigo M. F. de Andrade se aposenta e é sucedido pelo arquiteto Renato Soeiro, simbolizando o fim da fase heróica. Ao contrário do antigo diretor, Renato não goza do mesmo prestígio e tem maiores dificuldades para resolver entraves burocráticos. Essa situação demonstra o quanto até o momento o órgão era dependente de uma figura carismática, com bom relacionamento entre autoridades e intelectuais. No entanto, no plano executivo, Soeiro manteve a política do antecessor e sua direção é marcada pela continuidade do trabalho anterior (Fonseca, 2005).

Se a instauração de um governo democrático em 1945 não afetou a política de preservação no Brasil, que manteve sua orientação até quase o final da década de 1960, o decênio seguinte previa maiores mudanças. Desde os anos de 1950, a política de desenvolvimento deu novo impulso para a industrialização, urbanização e interiorização do país, como na construção de Brasília. A valorização do solo urbano e o crescimento das cidades começaram a criar tensões com a preservação da malha urbana e, em tal ambiente de questionamentos, novas propostas receberam estímulo (Fonseca, 2005).

Em 1965, o SPHAN recorreu à Unesco para rever sua atuação. Nos anos seguintes, intensificaramse os discursos que citavam o valor econômico dos bens, buscando conciliar o desenvolvimento do país com as políticas de preservação. O turismo passa a ser um tema frequente nas questões patrimoniais, o que até hoje é uma discussão polêmica, devido aos riscos de "espetacularização" e "disneyficação", entre outras mudanças que revelam uma nova fase no órgão a partir de 1970 (Fonseca, 2005, p. 139-142). No que se refere a "disneyficação", Meneses (1999, p. 18) afirma que a idéia de "visitar o passado", por meio de processos de "museificação do chamado Patrimônio 
Cultural", acaba por reduzir o passado a mero presente anacrônico, "fetichizado e congelado".

No ano de 1975, foi criado por Aloísio Magalhães e equipe o Centro Nacional de Referência Cultural (CNRC). Sua proposta era estudar uma nova política para o patrimônio cultural condizente com a realidade brasileira. Assim sendo, desenvolveu projetos culturais em quatro áreas ainda pouco exploradas no âmbito federal: artesanato; levantamentos socioculturais; história da tecnologia e da ciência no Brasil; levantamento de documentação sobre o Brasil (Gonçalves, 2002). Apesar de seu sucesso ter sido maior no campo discursivo do que em ações concretas, as propostas do CNRC foram incorporadas à nova políitica do SPHAN em 1979, no mesmo ano em que Aloísio Magalhães assume sua direção.

Para Fonseca (2005), o CNRC, com o objetivo de atualizar a reflexão sobre a realidade brasileira, aproximasse das preocupações da Semana de 22. Formado por professores da Universidade de Brasília, o grupo ia além das finalidades do SPHAN, de eleger os símbolos da nação, buscando "indicadores para a elaboração de um modelo de desenvolvimento apropriado às necessidades nacionais". Com esse caráter inovador, os conceitos formulados pelo órgão contribuíram, na década de 1980, para a política da Secretaria de Cultura do MEC e as questões patrimoniais na Constituição Federal de 1988.

Neste ambiente de mudanças, Aloísio Magalhães se opõe aos discursos de Rodrigo Melo Franco de Andrade. Inicialmente, prefere utilizar a expressão "bens culturais", mais abrangente do que "patrimônio histórico e artístico". Dá maior ênfase ao presente do que ao passado e assinala a importância de um maior contato com as populações locais. Além disso, elege a diversidade cultural do Brasil como cerne de seus discursos, em uma tentativa de ampliar a noção de patrimônio até o momento utilizada. Desse modo, pode-se considerar que Aloísio, quatro décadas depois, aproxima-se mais das idéias do anteprojeto de Mário de Andrade do que de Rodrigo em sua política. "Em oposição ao enredo da narrativa de Rodrigo, articulado pelas idéias de "civilização" e "tradição", a estória narrada por Aloísio é articulada pelas noções de "desenvolvimento" e "diversidade cultural" (Gonçalves, 2002, p. 51).

Ao contrário de Melo Franco de Andrade, Magalhães não vê a cultura africana e ameríndia em um estágio de evolução inferior à européia. Baseado na diversidade, classifica todas como atuais, em processo contínuo de transformação. Ao conceber a cultura brasileira no plural, utiliza as categorias de "povo", "segmentos sociais", "comunidades", destacando a heterogeneidade da população. Outra contribuição sua foi superar a barreira dos bens móveis e imóveis e pensar as práticas sociais também como patrimônios, para as quais bastaria a liberdade de expressão e os recursos necessários para continuar a existirem. Dessa forma, podemos observar nos discursos de Aloísio Magalhães uma preocupação, ainda não sistematizada em forma de leis e projetos, com o que hoje é denominado patrimônio intangível. Nesse contexto discursivo, a indiferença da população com o patrimônio não se deve ao fato de ela não conhecer os valores das obras consideradas excepcionais, como Melo Franco de Andrade pensava, mas à sua falta de representatividade nas obras tombadas, vinculadas apenas às elites e não a toda a nação (Gonçalves, 2002). Como observa Durham (1984, p. 32), ao analisar as relações entre cultura, patrimônio e preservação, "as classes dominantes dirigem a produção material e cultural coletiva, da qual se apropriam privilegiadamente".

Destacamos, entretanto, que tais concepções de Aloísio Magalhães referem-se ao campo discursivo, pois muitas de suas opiniões não se concretizaram na prática. Acreditamos ser este um dos pontos centrais quando se discute o patrimônio cultural no Brasil, pois há uma enorme distância entre o que foi dito e o que foi feito. As ações ainda estão muito aquém do que foi defendido por ele e Mário de Andrade em seu anteprojeto.

Contudo, no contexto dos anos 80 e com a atmosfera de renovação trazida por Aloísio Magalhães, as idéias apresentadas simbolizam uma nova fase para os discursos de patrimônio no Brasil. Essa mudança de perspectiva, iniciada com o CNRC, culmina em uma nova definição de patrimônio cultural pela Constituição Federal de 1988. Para a Constituição, constituem o patrimônio cultural brasileiro:

os bens de natureza material e imaterial, tomados individualmente ou em conjunto, portadores de referência à identidade, à ação, à memória dos diferentes grupos formadores da sociedade brasileira, nos quais se incluem: 
I. as formas de expressão;

II. os modos de criar, fazer e viver;

Ill.as criações científicas, artísticas e tecnológicas;

IV. as obras, objetos, documentos, edificações e demais espaços destinados às manifestações artístico-culturais;

V. os conjuntos urbanos e sítios de valor histórico, paisagístico, artístico, arqueológico, paleontológico, ecológico e científico (Brasil, 1988).

Verifica-se, nessa definição, que, ao contrário de exigir um caráter excepcional ao bem a ser tombado, como no Decreto-Lei de 1937, a Constituição privilegia o valor que tal bem representa para os grupos sociais. Portanto mais importante que as características físicas do bem é o que ele significa para a sociedade, que constantemente lhe atribui sentidos. É estudar as relações sociais que permitem a seleção de um bem como representativo para a identidade, memória e ação das diferentes camadas sociais. Nessa concepção, discutir o patrimônio requer conhecer a cultura daqueles que atribuíram tal valor, pois como aponta García Canclini (2007, p. 41), "a cultura abarca o conjunto de processos sociais de produção, circulação e consumo da significação na vida social" (grifos do autor).

Outro ponto de mudança é que, enquanto em 1937 o patrimônio está dividido em bens móveis e imóveis, agora abrange os bens de natureza material e imaterial. Desse modo, ir além do patrimônio de "pedra e cal" abre um caminho para discutir a valorização e preservação de práticas culturais, como festas, culinária, lendas e outros fazeres e saberes, e examinar se o tombamento, como até então era feito, seria a melhor forma de preservá-las. No entanto, como já apontamos ao longo do texto que devemos separar os discursos das ações quando se refere ao patrimônio cultural, não foi isso o que aconteceu.

Segundo Fonseca (2003), o legislador atribui o tombamento apenas aos incisos IV e $\mathrm{V}$ do texto constitucional, pois são os únicos que permitem a proteção da integridade física das obras. Dessa forma, "o que deveria ser uma das modalidades de formação desse patrimônio terminou por ser, durante mais de sessenta anos, a única disponível". Apesar da citação de outros bens passiveis de classificação como patrimônio cultural brasileiro, as ações desenvolvidas ao longo dos trabalhos do SPHAN apreendiam somente os bens móveis e imóveis, o que pouco mudou depois da Constituição de 1988.

Podemos considerar que a partir da década de 70 e, principalmente, 80, a política do patrimônio cultural foi criticada e começou a passar por um período de transição. Transformações também são percebidas em relação às solicitações de tombamentos: se antes consistiam num ato essencialmente interno, desse momento em diante ocorre um aumento substancial das solicitações externas, o que significa uma maior participação da sociedade no SPHAN, apesar de as decisões continuarem no âmbito dos técnicos (Fonseca, 2005).

Os tipos de bens tombados ampliam-se. Além da arquitetura religiosa e militar, aumenta o número de conjuntos, áreas industriais, construções em estilos arquitetônicos como o eclético, antes renegado pelos intelectuais, e obras referentes a grupos até então marginalizados, como imigrantes e grupos religiosos africanos. Um exemplo é o terreiro de candomblé Casa Branca, em Salvador. O Conselho do SPHAN estava dividido sobre o tombamento do terreiro pelo local não apresentar um valor excepcional ou artístico que justificasse tal resolução. $\bigcirc$ que alguns conselheiros não compreendiam era o valor social desse bem, como representante da cultura afro-brasileira, há mais de cento e cinquenta anos. $\bigcirc$ sucesso do tombamento na época, 1984, representou uma mudança em relação ao patrimônio até então privilegiado, o luso-brasileiro (Velho, 2006).

Entretanto o fim prático desta política - o modo de se proteger e preservar - não sofreu reformulações. "Os instrumentos de proteção continuam praticamente os mesmos: o tombamento para bens imóveis e os museus para a guarda dos bens móveis" (Fonseca, 2005 , p. 217), o que demonstra a necessidade de novas pesquisas para propor e examinar outras formas de proteção.

\section{CAMINHOS A SEREM TRILHADOS}

Novas discussões podem surgir com uma maior participação dos municípios nas questões patrimoniais. Apesar de a formação de regionais do SPHAN ser uma realidade desde sua criação, com o intuito de inventariar as obras de todos os cantos do país (Gonçalves, 2007), pouco ainda foi feito a nível local. Mesmo com exemplos 
como o Departamento de Cultura de São Paulo, dirigido por Mário de Andrade, como já citado, a preocupação das médias e pequenas cidades com o seu patrimônio cultural ainda é incipiente, senão inexistente. Para Monnet (1996), há não mais de trinta anos que a proteção do patrimônio cultural se tornou um instrumento de gestão urbana, com aparatos legais e sociais.

Losnak (2004) explica, por exemplo, que somente a partir da Lei $n^{\circ}$ 9.205, de 28 de dezembro de 1965, instituiu-se a obrigatoriedade de um Plano Diretor para as cidades do Estado de São Paulo que solicitassem o direito de auxílio financeiro ou empréstimo, e que é nesses planos que encontramos algumas das primeiras iniciativas municipais em relação ao patrimônio urbano. Em Ribeirão Preto, uma cidade do Estado com uma população atual em torno de meio milhão de habitantes, o Conselho de Defesa do Patrimônio Histórico e Cultural do município foi criado apenas em 1971 (Ribeirão Preto, 2004). Em Santa Rosa de Viterbo, uma pequena cidade da mesma região, com uma população atual em torno de vinte e três mil habitantes, - Conselho Municipal de Preservação do Patrimônio Histórico, Artístico, Paisagístico e Cultural foi criado no ano de 2006 (Santa Rosa de Viterbo, 2006). E não é de se espantar que muitas cidades do país não apresentem sequer uma política em relação ao seu patrimônio cultural local. $\bigcirc$ que se vê é que o tombamento federal continua sendo o de maior prestigio e o que efetivamente garante a proteção de um bem.

Acreditamos que pensar em discursos e ações além do atual Instituto do Patrimônio Histórico e Artístico Nacional (IPHAN) permitirá uma maior reflexão sobre o valor de excepcionalidade, valor nacional, estadual e local, incentivará medidas de proteção que superem o vigente conceito de tombamento e incluirá na categoria dos bens culturais expressões que podem ser consideradas irrelevantes até mesmo a nível regional, mas de extrema importância para pequenos grupos sociais que, ao se identificarem nelas, permitem sua reprodução e garantem sua permanência.

Outro aspecto positivo é que, com a maior participação dos municípios na valorização e preservação do patrimônio cultural, a população estará mais próxima do cerne das decisões, o que pode aumentar o interesse e participação social nestas discussões. Como diz Marilena Chauí (1992, p. 45):
Estado não pode colocar-se como centro de onde se define e se irradia a memória, pois ao fazê-lo destrói a dinâmica e a diferenciação interna da memória social e política; não pode ser produtor da memória nem o definidor do que pode e deve ser preservado. O Estado deve comportar-se como serviço público aos cidadãos [...].

Entretanto, apesar de muito ainda estar por ser feito, no que se refere ao patrimônio imaterial ou intangível, citado na Constituição Federal de 1988, observam-se, a partir do final dos anos 90, no Brasil, iniciativas para que sua preservação fosse realmente discutida e aplicada. Em novembro de 1997, aconteceu em Fortaleza o Seminário "Patrimônio Imaterial: Estratégias e Formas de Proteção", que, ao final, produziu a Carta de Fortaleza, com recomendações sobre o tema.

Entre as propostas do documento estão, entre outras: "que o IPHAN promova o aprofundamento da reflexão sobre o conceito de bem cultural de natureza imaterial"; "que seja constituído um banco de dados acerca das manifestações culturais passíveis de proteção, tomando a difusão e o intercâmbio das informações ágil e acessível"; "desenvolvido um Programa Nacional de Educação Patrimonial"; "estabelecida uma Política Nacional de Preservação do Patrimônio Cultural com objetivos e metas claramente definidos" (Instituto ..., 1997).

Essa preocupação com o patrimônio intangível culminou no Decreto $n^{\circ} 3.551$, de 4 de agosto de 2000, que cria o programa nacional do patrimônio imaterial e institui o registro dos bens culturais de natureza imaterial. Apesar de não abranger todas as recomendações da Carta de Fortaleza, o Decreto pode ser considerado um marco dessa política, pois cria instrumentos legais para a preservação do patrimônio intangível.

Para isso, institui quatro livros de registros: dos Saberes; das Celebrações; das Formas de Expressão; dos Lugares, este último referente a espaços onde se concentram e reproduzem práticas culturais coletivas, e não a construções arquitetônicas em si. Para ser registrado, o bem deve apresentar praticamente as mesmas características definidas pela Constituição de 1988, "relevância nacional para a memória, a identidade e a formação da sociedade brasileira". 
Ainda, o título recebido passa por uma revalidação a cada dez anos, e, caso não seja mais considerado Patrimônio Cultural do Brasil, deverá ser mantido apenas o registro como referência do seu tempo (Brasil, 2000).

A partir desse Decreto, novos bens começam a ser considerados patrimônio cultural brasileiro, o que incentiva novas discussões. Em 2002, a pintura corporal e arte gráfica Kusiwa dos índios wajãpi, do Amapá, torna-se o primeiro bem a ser registrado no Livro dos Saberes. Abreu (2003b), ao analisar os "patrimônios emergentes", aponta o patrimônio genético, que compreenderia desde a conservação da biodiversidade, os processos de clonagem e projetos do genoma, como um tema a ser examinado. Músicas, festas, pratos regionais, linguagens, ofícios, entre outros, passam a ser analisados pelo IPHAN para futuros registros, e o campo do patrimônio cultural amplia-se. Portanto essa abrangência vem a demonstrar que a noção de patrimônio intangível não se restringe somente ao folclore e à cultura popular, apesar de estarem entre os mais beneficiados com essa nova postura patrimonial.

Segundo Sant'anna (2003), a experiência de países subdesenvolvidos, em desenvolvimento e asiáticos, em relação aos seus patrimônios, aponta para práticas de preservação que, ao contrário de preocuparem-se somente com a materialidade, valorizam os conhecimentos e processos que permitem a existência de seus bens culturais.

Nos países mais pobres, essa concepção deve-se ao valor atribuído às criações populares, que revelam sua importância mais pelos fazeres e saberes do que por construções materiais. Já no mundo oriental, essa preocupação emerge das maneiras com tais culturas interagem com suas tradições. Para Sant'anna (2003, p. 49), "a permanência no tempo das expressões materiais dessas tradições não é o aspecto mais importante, e sim o conhecimento necessário para reproduzi-las". Desse modo, mais relevante que preservar um objeto é elaborar condições para transmitir o saber que o produz para as gerações presentes e futuras.

Argan (2005, p. 13), ao refletir sobre obras de arte, contribui para essa discussão. Para ele:

Uma vez que as obras de arte são coisas às quais está relacionado um valor, há duas maneiras de tratá-las. Pode-se ter preocupação pelas coisas: procurá-las, identificá-las, classificá-las, conservá-las, restaurá-las, exibilas, comprá-las, vendê-las; ou, então, pode-se ter em mente o valor: pesquisar em que ele consiste, como se gera e se transmite, se reconhece e se usufrui.

Tais iniciativas em relação ao patrimônio imaterial podem ser verificadas já na metade do século XX. Em 1950, o governo japonês concedeu a indivíduos detentores de conhecimentos e técnicas considerados importantes para o país o título de "Tesouros humanos vivos". Posteriormente, o governo também passou a considerar patrimônio cultural do Japão grupos coletivos, o que foi seguido por países como a República da Coréia, em 1964, Filipinas, em 1973 e Tailândia em 1985 (Abreu, 2003b).

Um exemplo bem sucedido no mundo ocidental é a França. Em 1994, o Ministério da Cultura do país concedeu o título de "Tesouros humanos vivos" a quase vinte pessoas, consideradas "mestres da arte". A esses mestres, para a preservação dos saberes, caberia "transmitir sua técnica a um aluno escolhido, na busca de perenização do seu ofício" (Abreu, 2003b, p. 85). Segundo a autora, os detentores desse "saber-fazer" podem ser chapeleiros, costureiros, restauradores, desde que a preservação de suas competências, muitas delas desenvolvidas ao longo de séculos, seja de interesse da nação francesa. E pelo o que se pode perceber do projeto, a transmissão do conhecimento é a melhor forma de preservação (Abreu, 2003b).

Retornando à realidade brasileira, podemos observar a preocupação com as manifestações e expressões culturais já no anteprojeto de Mário de Andrade, reformulado para a criação do Decreto-Lei n 25 de 1937, nos discursos de Aloísio Magalhães, na Constituição Federal de 1988. Dos discursos para as práticas, porém,, encontramos mudanças principalmente após o Decreto $n^{\circ} 3.551$ de 2000, referente ao patrimônio imaterial, o que implica enfatizar a necessidade, seja pelo pouco tempo desSas transformações, quanto pela manutenção de instrumentos insuficientes, de novas pesquisas e ações para que o patrimônio cultural brasileiro, móvel ou imóvel, material ou imaterial, melhor preserve, transmita e represente a diversidade cultural do país.

\section{Novos Horizontes para a Ciência da Informação}

Os estudos sobre o patrimônio cultural são marcados pela transdisciplinaridade. No início, um tema 
discutido principalmente por arquitetos, hoje é pesquisado também por historiadores, sociólogos, antropólogos e outros profissionais das Ciências Humanas. Acreditamos, no entanto, ao observarmos pesquisas que se aplicam a esse campo, mas que atualmente estão inseridas em outros contextos, que áreas como a Ciência da Informação ainda estão aquém do que poderiam contribuir.

Desse modo, propomos três linhas de pesquisa que ainda não foram desenvolvidas, de forma corrente, pela Ciência da Informação, mas que, pela bibliografia existente, apresentam caminhos promissores. A primeira é a relação entre patrimônio e o conceito de documento, a segunda sobre os processos documentais e o cientista da informação e a terceira que aborda a mediação e apropriação cultural do patrimônio.

Desde Paul Otlet, o que é um documento tem sido ponto de discussões. Para o advogado belga, em 1928, além de textos escritos, os objetos tridimensionais, como esculturas, artefatos, fósseis, obras de arte, objetos naturais, vestígios da atividade humana (como achados arqueológicos) são exemplos do que pode ser um documento, uma concepção que ele estendeu para o seu Tratado de Documentação de 1934 (Otlet, 1996). O que caracterizaria um documento, segundo Otlet, é sua capacidade de nos informar sobre algo, o que é possível não somente pelo uso de representações/ registros dos objetos, mas pela observação da própria obra em si.

Para Buckland (1991), apesar de observar que na literatura da Ciência da Informação há pouca discussão sobre os documentos não tradicionais, qualquer objeto pode tornar-se um documento se for utilizado para informar, dar a conhecer alguma coisa. Assim, a sua concepção valoriza os usos atribuídos aos objetos e não as intenções pelas quais foram elaborados.

Segundo seu raciocínio, a intenção pela qual um objeto foi criado não é decisiva para adquirir status de documento, pois, enquanto um livro produzido com o objetivo de informar pode não ser lido, obras com funções utilitárias ou estéticas podem testemunhar e informar sobre uma época, um ofício, uma região, etc. A finalidade de um objeto é atribuída pela sociedade, que o reformula constantemente, permitindo a Gondar e Dodebei (2005, p. 17) afirmar que os documentos são uma "montagem não só da sociedade que os produziu, como também das sociedades onde continuaram a viver, chegando até a nossa".
Suzanne Briet, em 1951, define documento como "qualquer signo físico em conceitual, preservado ou registrado, com a intenção de representar, reconstruir ou demonstrar um fenômeno físico ou conceitual" (Buckland, 1997, p. 806, tradução nossa) e enumera quatro características que todo documento deve apresentar: materialidade, intencionalidade, ter sido processado como documento e ter uma posição fenomenológica, ou seja, ser percebido como documento.

Em 1963, Ranganathan, ao contrário de Otlet, restringe seu conceito apenas a textos escritos, ao declarar explicitamente que objetos tridimensionais, inclusive os exibidos em museus, não podem ser documentos por não ser uma gravação em uma superfície mais ou menos plana, como o papel (Buckland, 1997). Para o teórico indiano, um documento deve ser apto à preservação ao longo do tempo e ao manejo físico e transporte (Martinez Comeche, 2006).

Somente nos anos de 1970, com um maior uso dos materiais audiovisuais, a noção de documento supera definitivamente os limites do texto escrito (Martinez Comeche, 2006), o que vem a demonstrar a diferença de concepções entre a Documentação e outras áreas do conhecimento, como a História, por exemplo, que desde o início do século XX considera tantos textos escritos como qualquer outro vestígio documental, inclusive os não intencionais, passíveis de adquirirem o mesmo valor documental (Bloch, 2001).

A diversidade dos testemunhos históricos é
quase infinita. Tudo que o homem diz ou escre-
ve, tudo que fabrica, tudo que toca e deve infor-
mar sobre ele. É curioso constatar o quão im-
perfeitamente as pessoas alheias a nosso tra-
balho avaliam a extensão dessas possibilida-
des. É que continuam a se aferrar a uma idéia
obsoleta de nossa ciência: a do tempo em que
não se sabia ler senão os testemunhos volun-
tários (Bloch, 2001, p. 79-80).

Tentando sintetizar as correntes da Documentação, introdutórias e fundamentais para a área, Martinez Comeche (2006, p. 37, tradução nossa) define documento como: "mensagem ou mensagens, incorporadas permanentemente a um suporte [...], empregado com uma finalidade informativa". Ainda no plano das definições, Le Coadic (2004, p.5) 
considera como documento "todo artefato que representa ou expressa um objeto, uma idéia ou uma informação por meio de signos gráficos e icônicos (palavras, imagens, diagramas, mapas, figuras, símbolos), sonoros e visuais (gravados em suporte de papel ou eletrônico)".

Desse modo, tudo pode ser um documento, desde que seja uma informação registrada em um suporte e/ou exerça uma função informativa? Para Dodebei (2000), essa definição não é suficiente "para diferenciar os documentos dos objetos", transformando quase tudo em documento, e não potencialmente documento. Assim sendo, a autora propõe uma definição que, em nossa opinião, contribui para esclarecer a discussão desenvolvida até o momento:

[...] documento é uma representação, um signo, isto é, uma abstração temporária e circunstancial do objeto natural ou acidental, constituído de essência (forma ou forma/conteúdo intelectual), selecionado do universo social para testemunhar uma ação cultural (Dodebei, 2000, p.66, grifo nosso).

Se considerarmos a concepção de Otlet, podemos entender que o patrimônio cultural informa sobre algo ao ser observado, pois são bens que receberam valores e foram divulgados para transmitir determinada imagem, ou seja, são documentos. Se utilizarmos as categorias de Briet, percebemos que essa afirmação se torna relativa, pois, apesar de apresentar materialidade (mesmo o patrimônio intangível se refere a objetos), o patrimônio só adquire intencionalidade após ser denominado dessa forma. $\bigcirc$ processo documental é realizado principalmente sobre os registros gerados e não sobre as obras em si, o que não permite consenso sobre a validade desse requisito, devido a sua posição fenomenológica ser algo extremamente subjetivo. Por fim, se nos apoiarmos em Ranganathan, praticamente excluímos o patrimônio cultural da categoria dos documentos, pois muitos são imóveis, o que impossibilita o manejo e transporte, além da grande maioria dos bens não estar preservado em uma superfície plana.

Como se vê, não há concordância sobre o que é um documento, aumentando ainda mais as incertezas quando a pergunta é se os bens considerados patrimônio cultural são documentos para a Ciência da Informação.
Para Smit (2003), um postulado básico da Ciência da Informação é que a informação deve ser registrada e estocada para o seu futuro uso. Para isso, instituições como arquivos e bibliotecas exerceriam a função de estocá-la, considerando seu caráter de utilidade. Desse modo, ocorreria o que, para o autor, pode ser denominado como a "institucionalização da informação".

Nessa perspectiva, o patrimônio cultural que não é móvel e, em algumas situações, não é de pequeno porte, não pode ser estocado para uso. $\bigcirc$ que se pode é armazenar informações sobre esses bens, gerando outros documentos, o que parece não condizer com os pressupostos de Smit (2003). No entanto, ao utilizarmos a definição genérica encontrada em grande parte da bibliografia atual, de documento como informação registrada em um suporte (Machado; Camargo, 2000; Rodríguez Bravo, 2002; Santos; Ribeiro, 2003), novamente podemos pensar o patrimônio como um documento para a Ciência da Informação.

Mais do que isso, rever os conceitos de patrimônio e de documento estimula reflexões sobre as possibilidades ou deveres da Ciência da Informação com essa tipologia de registro da memória social, que, em alguns casos, é de forma tão diversa dos chamados "documentos tradicionais".

Um diálogo possível, por exemplo, está na obra do historiador francês Jacques Le Goff (1982; 2003), que, ao discutir os conceitos de documento e monumento, também contribui para as relações que sugerimos neste artigo. Citando Foucalt, Le Goff (1982) considera que o documento, antes de informar, possui uma forma, que, além de ensinar, tem a capacidade de "impressionar", ou seja, na sua visão, um documento é sempre um monumento.

Para esse autor (2003), seguido por Fabris (2000, p. 138), o documento é um monumento por resultar "do esforço das sociedades históricas para impor ao futuro - voluntária ou involuntariamente determinada imagem de si próprias", desmistificando a visão positivista do século XIX, que tratava o documento como uma obra neutra e não uma escolha do historiador. Nessa abordagem contemporânea, o documento é visto como uma construção social, deste o momento que ele foi produzido até os significados a eles atribuídos pelas gerações futuras. 
Quer se trate de documentos conscientes ou inconscientes (traços deixados pelos homens sem a mínima intenção de legar um testemunho a posteridade), as condições de produção do documento devem ser minuciosamente estudadas. As estruturas do poder de uma sociedade compreendem o poder das categorias sociais e dos grupos dominantes ao deixarem, voluntariamente ou não, testemunhos suscetíveis de orientar a história num ou noutro sentido; o poder sobre a memória futura, o poder de perpetuação, deve ser reconhecido e desmontado pelo historiador. Nenhum documento é inocente. Deve ser analisado (Le Goff, 1982, p. 110).

Outro tópico a ser estudado pela C. I. é o registro e o tratamento documental realizados sobre os bens considerados patrimônio cultural. Segundo Silva (1996), a própria idéia de preservação baseia-se na identificação, registro, proteção, tombamento, divulgação e promoção do patrimônio cultural, processo que durante muito tempo não foi realizado por ou com o auxílio de profissionais da informação.

O próprio Mário de Andrade, em suas viagens pelo Brasil, revela a preocupação com as formas de registro e sua posterior representação. Como mostramos, ele escolhe a fotografia e a microfilmagem como suporte para as informações, além de inserir diversos detalhamentos para descrever cada registro produzido.

Já em 1975, a política do patrimônio destaca a importância de um tratamento documental ao inserir, entre o quadro de profissionais do Centro Nacional de Referência Cultural, documentalistas, e colocar entre os objetivos do órgão o levantamento de documentação sobre o Brasil. Na Carta de Fortaleza, de 1997, encontramos a recomendação de criação de um banco de dados acerca das manifestações culturais do país, permitindo o acesso e difusão de informações de forma ágil. Observa-se, portanto, nesses exemplos, a importância de profissionais qualificados para tratar de informações nos mais variados níveis e ambientes.

No que se refere ao tratamento da documentação sobre o patrimônio cultural, não vemos necessidade de mudanças de conduta, opondo-se às já aplicadas em bibliotecas, arquivos e museus. Acreditamos, no entanto, que o profissional da informação também tem condições de auxiliar na identificação, seleção, preservação, divulgação e promoção das obras em si. Desse modo, além do valor de utilidade, o cientista da informação deve analisar os valores culturais, históricos, estéticos, econômicos, entre outros, de uma obra e estudar procedimentos que são aplicáveis e eficientes para bens que não podem ser estocados diretamente em instituições informacionais.

Araripe (2004, p. $114-115)$, em um dos poucos trabalhos que discute a importância do patrimônio cultural para a Ciência da Informação, acredita que a inserção dessa temática na área exige uma mudança de perspectiva, principalmente da Biblioteconomia:

Queremos na verdade afirmar que a área biblioteconômica precisa ampliar o raio das conhecidas e tradicionais fontes de informação, desse conceito linear que olha apenas para aquilo que conseguimos juntar ou agrupar de forma ordenada e organizada. Há que se pensar em um acervo informacional que se encontra em qualquer lugar, de diferentes formas e sem nenhum ordenamento planejado, mas que diz muito da cultura e da história das pessoas e dos lugares. É um acervo dinâmico, pois é construído pelo movimento da vida.

No entanto essa postura novamente leva-nos a refletir sobre o que é informação, os limites da C. I. e, consequentemente, o papel desse profissional. $\mathrm{Na}$ concepção de Le Coadic (2004, p. 55), "a Ciência da Informação é uma ciência rigorosa que tem por objeto o estudo das propriedades gerais da informação natureza, gênese, efeitos -, e a análise de seus processos de construção, comunicação e uso", o que é condizente com o que pontuamos, de relacionar a informação não somente a determinados tipos de suportes - o que não significa negá-los - e instituições. $\bigcirc$ essencial, como afirma o autor, é pensar a informação a partir do ser social que a procura, que pode encontrá-la em qualquer lugar, em qualquer vestígio, desde que possua condições de acesso e uso. De qualquer modo, apresentamos uma possibilidade que, se for mais bem estudada, pode revelar novos campos de pesquisa e trabalho para o cientista da informação ou apontar os equívocos de considerar esse tópico como objeto de estudo da área.

Por último, citamos a mediação e apropriação cultural do patrimônio. Para Coelho (1997, p. 248), e grande parte da bibliografia disponível, a mediação 
cultural consiste em "promover a aproximação entre indivíduos ou coletividades e obras de cultura e arte" para que as pessoas inventem seus próprios fins no reconhecimento e compreensão de um bem ou atividade cultural. Desse modo, caberia a um profissional especializado servir como intermediário, que no papel de mediador facilitaria tal aproximação.

Na maioria das vezes, a mediação cultural é discutida e aplicada no âmbito de bibliotecas e museus. Os processos de ensino-aprendizagem, a construção do conhecimento (Gomes, 2008), a capacitação do bibliotecário (Dias et al., 2004) e o papel da biblioteca escolar são temas recorrentes na Ciência da Informação, e, em muitos desses trabalhos, a mediação cultural é apresentada como uma ação realizada em bibliotecas. Ao mesmo tempo, a tríade obra - autorespectador (Lara Filho, 2006) e as práticas com o público (Santo, 2006) são tópicos que apontam para a relação dos museus com a mediação cultural. Apesar de haver trabalhos que abordam a mediação de forma conceitual e interdisciplinar, como Almeida (2007), são poucas as pesquisas que discutem tais processos de aproximação e intermediação fora dessas instituições, o que produz um quadro insuficiente em relação à diversidade de usos dessa expressão, seja na C.I. como em áreas afins:

A idéia de mediação acaba por cobrir coisas tão diferentes entre si, que vão das velhas concepções de "atendimento ao usuário" à atividade de um agente cultural em uma dada instituição - museu, biblioteca, arquivo, centro cultural -, à construção de produtos destinados a introduzir o público num determinado universo de informação e vivências (arte, educação, ecologia, por exemplo), à elaboração de políticas de capacitação ou acesso às tecnologias de informação e comunicação, etc. Desse modo, uma definição consensual de mediação parece impraticável: sempre contextualizada, torna-se um conceito plástico que estende suas fronteiras para dar conta de realidades muito diferentes entre si.

Realidade parecida encontra-se quando discutimos a apropriação cultural. Segundo Perrotti e Pieruccini (2007), na Era da Informação, quando cada vez mais temos disponível uma imensa quantidade de informações, informar e informar-se requerem dominar um conjunto de fazeres e saberes especiais e especializados. Somente dominando os processos de produção de sentidos e significados é que os indivíduos serão capazes de se apropriar dos bens culturais e, efetivamente, fazer uso da informação. Para isso, priorizam a escola e a biblioteca escolar como ambiente para esse treinamento cultural. De certa forma, os autores aproximam-se de Bourdieu ao citar a escola como um dos meios de se apropriar dos instrumentos de decodificação dos bens culturais (Bourdieu; Darbel, 2003).

Portanto, seja nos trabalhos de mediação quanto de apropriação cultural, o que predomina é a relação Informação - Educação. Somente pela educação é que os indivíduos sociais poderiam participar, de forma afirmativa, dos processos simbólicos, apropriando-se da informação e cultura. E para que essas aprendizagens se efetuem, desenvolve-se a mediação cultural, que, na perspectiva de Perrotti e Pieruccini (2007), não se restringe apenas ao trabalho dos profissionais da informação, mas a todos os elementos dos dispositivos informacionais. Desse modo, seria possível desenvolver saberes essenciais ao mundo contemporâneo, como saber informar-se, avaliar, explorar, contextualizar, associar, entre outros; e a formação, ao contrário de um ato de transmissão e transferência de conhecimentos por mecanismos repetitivos, priorizaria o reconhecimento de analogias, relações (Perrotti; Verdini, 2008; Pieruccini, 2004).

O que queremos enfatizar é que a Ciência da Informação tem produzido uma significativa bibliografia sobre mediação cultural e, mais recentemente, apropriação cultural. Essas reflexões geralmente têm sido feitas a partir de bibliotecas e museus, o que, pela importância como instituições culturais e lugar de trabalho para a maioria os cientistas da informação, é totalmente justificável. Entretanto, justamente pela abrangência e possibilidades das pesquisas, acreditamos que tais discussões também podem ser realizadas em ambientes além dos citados, que, de alguma forma, armazenam registros da memória social. Para nós, um destes lugares é a cidade e os registros do patrimônio cultural.

Segundo Le Coadic (2004, p. 42), durante muitos anos, a Biblioteconomia e Documentação priorizou o fornecimento do documento, com ênfase no objeto, no livro e não nas informações, o que levou a não se questionar se as necessidades informacionais foram satisfeitas. Hoje, o que se começou a perceber é 
a exigência de considerar o impacto da informação na vida dos indivíduos, não necessariamente atrelada a um ambiente ou sistema de informação específico.

Desse modo, ao considerarmos o patrimônio cultural como fonte de informação, registro da memória social, identificado, classificado, registrado, preservado e difundido, poderemos propor mediações a serem realizadas com esses bens e analisar como as informações que eles apresentam podem ser apropriadas pela população. Como escreve Araripe (2004, p. 122), é a "possibilidade de ver no patrimônio cultural, enquanto memória coletiva, uma valiosa fonte de informação para a pesquisa e para o ensino, capaz de promover a construção de um indivíduo atento ao processo de formação social".

\section{CONSIDERAÇÕES FINAIS}

O que é um patrimônio cultural tem levantando discussões desde o século XVIII. Especificamente no Brasil, a questão se tornou central apenas no século XX, mas já permitiu, em torno de um século, uma grande discussão teórica e a consolidação de instituições. As áreas do conhecimento que mais se apropriaram do tema no Brasil foram a Arquitetura, a História, a Antropologia e a Sociologia, enquanto buscamos defender neste artigo que a Ciência da Informação poderia exercer um papel mais representativo no que se refere ao patrimônio, principalmente nas interfaces com o que já está consolidado dentro do campo.

\section{REFERÊNCIAS}

ABREU, R. A emergência do patrimônio genético e a nova configuração do campo do patrimônio. In: ABREU, R.; CHAGAS, M. (Orgs.). Memória e patrimônio: ensaios contemporâneos. Rio de Janeiro: DP\&A, 2003a. p. 30-45.

ABREU, R. "Tesouros humanos vivos" ou quando as pessoas transformam-se em patrimônio cultural: notas sobre a experiência francesa de distinção do "Mestre da Arte". In: ABREU, R.; CHAGAS, M. (Orgs.). Memória e patrimônio: ensaios contemporâneos. Rio de Janeiro: DP\&A, 2003b. p. 81-94.

ALMEIDA, M. A. de. Mediação cultural e da informação: considerações socioculturais e políticas em torno de um conceito. In: ENCONTRO NACIONAL DE PESQUISA EM CIÊNCIA DA IN-
Discutir o patrimônio cultural permitiu repensar o conceito de documento, essencial para a C.I. desde o início da Documentação, com Paul Otlet. Ao mesmo tempo, situamos esse conceito na relação com outras disciplinas, o que foi possível, por exemplo, ao abordarmos obras clássicas de historiadores como Marc Bloch e Jacques Le Goff.

Posteriormente, propomos ampliar o campo de atuação do profissional da informação ao defender que ele não deve ocupar-se apenas da documentação produzida sobre o patrimônio cultural, mas também da identificação, seleção, classificação e difusão das obras em si, independentemente de estarem em instituições como bibliotecas, arquivos e museus. Tal concepção não poderia ser diferente, se consideramos o patrimônio cultural um documento para a Ciência da Informação.

Por fim, tratamos de um tema que cada vez mais tem recebido atenção da área: a mediação e apropriação cultural. Se apenas o acesso à informação é insuficiente na contemporaneidade, devemos pensar instrumentos para que os indivíduos realmente consigam apropriar-se dos bens culturais. No entanto, quando o ambiente pode ser a própria cidade, as discussões ampliam-se e relevam os diferentes usos e a abrangência desses conceitos.

Como vimos, já existem alguns trabalhos na Ciência da Informação que têm contribuído para o desenvolvimento dessas discussões, mas ainda em pequeno número em relação às possibilidades que tentamos mostrar. Desse modo, esperamos que este artigo venha a contribuir para os novos horizontes que se apresentam.
FORMAÇÃO, 8., 2007, Salvador. Anais eletrônicos...Salvador: ENANCIB, 2007. Disponível em: < http:// www.enancib.ppgci.ufba.br/artigos/GT3-212.pdf > . Acesso em: 03 ago. 2008.

ARANTES, A. A. (Org.). Produzindo o passado: estratégias de construção do patrimônio cultural. São Paulo: Brasiliense, 1984.

ARARIPE, F. M. A. Do patrimônio cultural e seus significados. Transinformação, v. 16, n. 2, p. 111 -122, 2004. Disponível em: $<$ http://revistas.puc-campinas.edu.br/transinfo/ viewarticle.php?id=63>. Acesso em: 30 mar. 2009.

ARGAN, G. C. História da arte como história da cidade. 5. ed. São Paulo: Martins Fontes, 2005. 
BLOCH, M. Apologia da História ou, O ofício de historiador. Rio de Janeiro: Jorge Zahar Editor, 2001.

BOSI, A. História concisa da literatura brasileira. 44. ed. São Paulo: Cultrix, 2007.

BOURDIEU, P.; DARBEL, A. O amor pela arte: os museus de arte na Europa e seu público. São Paulo: EDUSP; Zouk, 2003.

BRASIL. Constituição (1988). Disponível em: < http:// www.planalto.gov.br/ccivil 03/constituicao/ constitui\%C3\%A7ao.htm>. Acesso em: 28 ago. 2008.

BRASIL. Decreto n ${ }^{\circ} 3.551$, de 4 de agosto de 2000. Institui o registro de bens culturais de natureza imaterial que constituem patrimônio cultural brasileiro, cria o Programa Nacional do Patrimônio Imaterial e dá outras providências. Disponível em: < http://www.cultura.gov.br/legislacao/direitos_autorais/legislacao/ index. php? $p=1082 \&$ more $=1 \& c=1 \& p b=1>$. Acesso em: $17 \mathrm{dez}$. 2008.

BRASIL. Decreto-lei n 25, de 30 de novembro de 1937. Organiza a proteção do patrimônio histórico e artístico nacional. Disponível em: <http://www.planalto.gov.br/CCIVIL/Decreto-Lei/ Del0025.htm >. Acesso em: 28 ago. 2008.

BUCKLAND, M. K. Information as thing. Journal of the American Society for Information Science, v. 42, n.5, p.351-360, 1991 Disponível em: < http://people.ischool.berkeley.edu/ buckland/ thing.html>. Acesso em: 17 ago. 2007.

BUCKLAND, M. K. What is a document? Journal of American Society for Information Science, v.48, n.9, p.804-809, 1997. Disponível em: <http://www.ischool.berkeley.edu/ buckland/ whatdoc.html >. Acesso em: 14 maio 2007.

CÂNDIDO, A. Literatura e sociedade: estudos de teoria e história literária. 10. ed. Rio de Janeiro: Ouro sobre Azul, 2008.

CHAGAS, M. O pai de Macunaíma e o patrimônio espiritual. In: ABREU, R.; CHAGAS, M. (Orgs.). Memória e patrimônio: ensaios contemporâneos. Rio de Janeiro: DP\&A, 2003. p. 95-108.

CHAUÍ, M. Política cultural, cultura política e patrimônio histórico. In: SÃO PAULO. Secretaria Municipal de Cultura. O direito à memória: patrimônio histórico e cidadania. São Paulo: Departamento do Patrimônio Histórico, 1992. p. 37 46.

CHOAY, F. A alegoria do patrimônio. São Paulo. Estação Liberdade; Editora UNESP, 2001.

COELHO, Teixeira. Dicionário crítico de política cultural. São Paulo: lluminuras, 1997.

DIAS, M. M. K.; et al. Capacitação do bibliotecário como mediador do aprendizado no uso de fontes de informação. Revista Digital de Biblioteconomia e Ciência da Informação, v. 2, n. 1, p. 1-16, 2004. Disponível em: < http://server01.bc.unicamp.br/ seer/ojs/viewarticle.php?id=22 > . Acesso em: 03 ago. 2008.
DODEBEI, V. Construindo o conceito de documento. In: LEMOS, Teresa; MORAES, Nilson (Orgs.). Memória e construções de identidades. Rio de Janeiro: 7 Letras, 2000. p.59-66.

DURHAM, E. R. Cultura, patrimônio e preservação: texto II. In: ARANTES, A. A. (Org.). Produzindo o passado: estratégias de construção do patrimônio cultural. São Paulo: Brasiliense, 1984. p. 23-58.

FABRIS, A. Fragmentos urbanos: representações culturais. São Paulo: Studio Nobel, 2000

FONSECA, M. C. L. O patrimônio em processo: trajetória da políitica federal de preservação no Brasil. 2. ed. rev. e ampl. Rio de Janeiro: Editora UFRJ; MinC - IPHAN, 2005.

FONSECA, M. C. L. Para além da pedra e cal: para uma concepção ampla de patrimônio cultural. In: ABREU, R.; CHAGAS, M. (Orgs.). Memória e patrimônio: ensaios contemporâneos. Rio de Janeiro: DP\&A, 2003. p. 56-76.

GARCÍA CANCLINI, N. Diferentes, desiguais e desconectados: mapas da interculturalidade. 2. ed. Rio de Janeiro: Editora UFRJ, 2007.

GOMES, H. F. A mediação da informação, comunicação e educação na construção do conhecimento. DataGramaZero, v.9, n. 1, p. 1-16, 2008. Disponível em: < http://www.dgz.org.br/fev08/ Art_01.htm>. Acesso em: 20 dez. 2008.

GONÇALVES, C. S. Restauração arquitetônica: a experiência do SPHAN em São Paulo, 1937-1975. São Paulo: Annablume; FAPESP, 2007

GONÇALVES, J. R. S. A retórica da perda: os discursos do patrimônio cultural no Brasil. 2. ed. Rio de Janeiro: Editora UFRJ; IPHAN, 2002.

GONDAR, J.; DODEBEI, V. (Orgs.). O que é memória social? Rio de Janeiro: Contra Capa, 2005.

HOBSBAWN, E.; RANGER, T. (Orgs.). A invenção das tradições. 5. ed. São Paulo: Paz e Terra, 2008.

HOOPER-GREENHILL, E. I musei e la formazione del sapere: le radici storiche, le pratiche del presente. Milano: II Saggiatore, 2005.

INSTITUTO DO PATRIMÔNIO HISTÓRICO E ARTÍSTICO NACIONAL (IPHAN). Carta de Fortaleza. In: SEMINÁRIO PATRIMÔNIO IMATERIAL: estratégias e formas de proteção, 1997, Fortaleza. Anais eletrônicos... Fortaleza: IPHAN, 1997. Disponível em: <http://portal.iphan.gov.br/portal/baixaFcdAnexo.do? $\mathrm{id}=268>$. Acesso em: 17 dez. 2008.

LAFETÁ, J. L. 1930: a crítica e o modernismo. 2. ed. São Paulo: Duas Cidades; Editora 34, 2000.

LARA FILHO, D. de. O museu como um espaço relacional. In: ENCONTRO NACIONAL DE PESQUISA EM CIÊNCIA DA INFORMAÇÃO, 7., 2006, Marília. Anais eletrônicos...Marília: ENANCIB, 2006. Disponível em: <http://www. portalppgci. 
marilia.unesp.br/enancib/viewpaper.php?id=251 > . Acesso em: 03 ago. 2008.

LE COADIC. Y.-F. A ciência da informação. 2. ed. rev. e atual. Brasília: Briquet de Lemos, 2004.

LE GOFF, J. História e memória. 5 ed. Campinas: Editora da Unicamp, 2003.

LE GOFF, J. Reflexões sobre a história: entrevista de Francesco Maiello. São Paulo: Edições 70, 1982.

LOBATO, M. Idéias de Jeca tatu. São Paulo: Globo, 2008.

LOSNAK, C. J. Polifonia urbana: imagens e representações: Bauru 1950-1980. Bauru: Edusc, 2004.

MACHADO, H. C.; CAMARGO, A. M. de A. Como implantar arquivos públicos municipais. 2. ed. São Paulo: Arquivo do Estado; Imprensa Oficial, 2000.

MARTÍNEZ COMECHE, J. A. El documento. In: LÓPEZ YEPES, J. (Coord.). Manual de ciencias de la documentación. 2. ed. Madrid: Ediciones Pirâmide, 2006. p. 33-38.

MENESES, U. T. B. de. A crise da memória, história e documento: reflexões para um tempo de transformações. In: SILVA, Z. L. da (Org.). Arquivos, patrimônio e memória: trajetórias e perspectivas. São Paulo: Editora Unesp; FAPESP, 1999. p. 11-29.

MONNET, J. O álibi do patrimônio: crise da cidade, gestão urbana e nostalgia do passado. Revista do Patrimônio Histórico e Artístico Nacional: Cidadania, n. 24, p.220-228, 1996.

NEEDELL, J. D. Belle Époque tropical: sociedade e cultura de elite no Rio de Janeiro na virada do século. São Paulo: Companhia das Letras, 1993.

NOGUEIRA, A. G. R. Por um inventário dos sentidos: Mário de Andrade e a concepção de patrimônio e inventário. São Paulo: Hucitec; FAPESP, 2005. (Estudos brasileiros; 39).

OTLET, P. El tratado de documentación: el libro sobre el libro: teoría y práctica. Murcia: Universidad de Murcia, 1996.

PERROTTI, E.; PIERUCCINI, I. Infoeducação: saberes e fazeres da contemporaneidade. In: LARA, M. L. G. de; FUJINO, A.; NORONHA, D. P. (Orgs.). Informação e contemporaneidade: perspectivas. Recife: NECTAR, 2007. p. 47-96.

PERROTTI, E.; VERDINI, A. S. Estações do conhecimento: espaços e saberes informacionais. In : ROMÃO, L.M.S. (Org.). Sentidos da biblioteca escolar. São Carlos: Alphabeto, 2008, p. 13-40.

PIERUCCINI, I. A ordem informacional dialógica: estudo sobre a busca de informação em Educação. São Paulo. 2004. 194f. Tese (doutorado em Ciência da Informação) - Escola de Comunicações e Artes, Universidade de São Paulo, São Paulo, 2004.
RABELLO, Rodrigo. A face oculta do documento: tradição e inovação no limiar da Ciência da Informação. 2009. 33 lf. Tese (doutorado em Ciência da Informação)-Universidade Estadual Paulista, Marília, 2009.

RIBEIRÃO PRETO. Lei Ordinária n 2508, de 21 de setembro de 1971. Cria o Conselho de Defesa do Patrimônio Histórico e Cultural do Município. Ribeirão Preto, 2004. Disponível em: $<$ http://www.ribeiraopreto.sp.gov.br/principal.asp?pagina=/leis/ pesquisa/pesquisa.php>. Acesso em: 29 dez. 2007.

RIEGL, A. I/ culto moderno dei monumenti: il suo carattere e i suoi inizi. 3. ed. Bologna: Nuova Alfa Editoriale, 1990.

RODRÍGUEZ BRAVO, B. El documento: entre la tradición y la renovación. Gijón: Ediciones Trea, 2002.

SANT'ANNA, M. A face imaterial do patrimônio cultural: os novos instrumentos de reconhecimento e valorização. In: ABREU, R.; CHAGAS, M. (Orgs.). Memória e patrimônio: ensaios contemporâneos. Rio de Janeiro: DP\&A, 2003. p. 46-55.

SANTA ROSA DE VITERBO. Lei $n^{\circ} 3054$, de 9 novembro de 2006. Dispõe sobre a criação do Conselho Municipal de Preservação do Patrimônio Histórico, Artístico, Paisagístico e Cultural de Santa Rosa de Viterbo, e dá outras providências. Disponível em: <http://www.bandasinfonicasrv.com/leidecriacao.php >. Acesso em: 28 ago. 2008.

SANTO, S. M. do E. A mediação do profissional da informação nas florestas da sociedade da informação. TransInformação, v. 18. n.2, p. 95-102, 2006. Disponível em: <http://revistas.puccampinas.edu.br/transinfo/viewarticle.php?id=149>. Acesso em: 20 dez. 2008.

SANTOS, G. C.; RIBEIRO, C. M. Acrônimos, siglas e termos técnicos: arquivística, biblioteconomia, documentação, informática. Campinas: Editor Átomo, 2003.

SEVCENKO, N. Literatura como missão: tensões sociais e criação cultural na Primeira República. 2. ed. rev. e ampl. São Paulo: Companhia das Letras, 2003.

SILVA, M. B. S. de R. Preservação na gestão das cidades. Revista do Patrimônio Histórico e Artístico Nacional: Cidadania, n. 24, p. 165-174, 1996.

SMIT, J. W. Arquivologia/Biblioteconomia: interfaces das Ciências da informação. Informação \& Informação, v.8, n. 1, 2003.

VELHO, G. Patrimônio, negociação e conflito. Mana, v. 12, n. 1, 2006. Disponível em: <http://www.scielo.br/ scielo.php?script=sci_arttext\&pid=S0104$93132006000100009 \& \mathrm{lng}=\mathrm{pt \& nrm}=$ iso $>$. Acesso em: 17 dez. 2008.

VIOLLET-LE-DUC, E. Restauração. São Paulo: Ateliê Editorial, 2001. 
